ORIGINAL ARTICLE

\title{
Body weight perception and weight management practices among a group of Sri Lankan university students
}

\author{
Karthikesu Karthijekan ${ }^{1}$, Ranil Jayawardena ${ }^{2}$, Angela Arulpragasam Anthony ${ }^{1}$, Kanagasingam Arulnithy ${ }^{3}$ \\ ${ }^{1}$ Faculty of Health-Care Sciences, Eastern University, Sri Lanka \\ ${ }^{2}$ Faculty of Medicine, University of Colombo, Sri Lanka \\ ${ }^{3}$ Teaching Hospital Batticaloa, Sri Lanka
}

Article Information

Total number of

Words 2905

Tables 02

Authors have no conflicts of interest to declare

Keywords: Weight perception, University students, Overweight, Obesity, Sri Lanka

Date of submission: 23.07 .2018

Date of acceptance: 28.12 .2018

Author responsible for correspondence: Mr. Karthikesu Karthijekan Department of Supplementary Health Sciences, Faculty of Health-Care Sciences No 50, New Kalmunai Road, Batticaloa Email:jeshikarthi@gmail.com

http://orcid.org/0000-0003-1222-3909

DOI: http://doi.org/10.4038/cjms. v55i2.4937

\begin{abstract}
Background:

The increasing trends in overweight and obesity is a public health issue globally. Self-perception of a person's weight may influence the action taken by the individual in his/her weight management.
\end{abstract}

\section{Objective:}

The present study aims to evaluate the association between selfperception of body weight, weight management practices and calculated body mass index (BMI) among a group of Sri Lankan university students.

\section{Method:}

A sample of 384 students was selected from the Eastern University, Sri Lanka by using a systematic sampling technique. A self-administered questionnaire assessed the socio-demographic characters, weight management practices and perception of existing body weight. Weight, height and waist circumference (WC) were measured and compared with Asian anthropometric cut-offs for BMI and WC. Chi-squire test was used to find out the association between selected variables and calculated BMI.

\section{Results:}

The response rate was $87.5 \%$. Out of 336 participants, the percentages of those overweight, obese and underweight were $35.2 \%, 10.7 \%$ and $8.6 \%$ respectively. Two- thirds of overweight males and a third of overweight females considered themselves as 'about right weight' or 'underweight'. In the obese subjects, $5.3 \%$ and $23.5 \%$ men and women respectively perceived themselves as 'about right weight'. Over two thirds of all obese subjects perceived themselves as being overweight. Of those who perceived themselves as overweight or very overweight, $71.2 \%$ tried to lose their weight. In the perceived 'normal weight category, $6.4 \%$ tried to lose weight.

\section{Conclusions:}

Body weight misperception was common among overweight and obese students. Among the perceived overweight or very overweight categories, two thirds attempted to lose their body weight. This study highlights the importance of self-awareness of body weight in maintaining a healthy body weight.

\section{Background}

Overweight and obesity are defined as abnormal or excessive fat accumulation in the body, which gives adverse health outcomes[1]. Obesity has reached epidemic proportions globally, with at least 2.8 million people dying each year due to their 
consequences[2]. Previously, it was mainly seen in high-income countries but now, it is recognized as an issue in low-and middle-income countries as well[2]. In 2016, World Health Organization (WHO) estimated that the obesity prevalence has tripled compared with that in 1975 and reports that over 1.9 billion and nearly 650 million adults are overweight and obese respectively[1]. Globally, the prevalence of overweight has been estimated as $39 \%$ in males and $40 \%$ in females while for obesity, the prevalence is $11 \%$ in males and $15 \%$ in females[1]. The epidemic of obesity, overweight and abdominal obesity has spread rapidly through the South Asian region[3]. Obesity has become an emerging public health problem in Sri Lanka as well[4]. Previous studies show a clear upward trend in age-adjusted obesity (Body Mass Index $(\mathrm{BMI}) \geq 25 \mathrm{~kg} / \mathrm{m}^{2}$ ) prevalence in Sri Lankan males and females; increasing from $14.3 \%$ (males) and $19.4 \%$ (females) in 2005 [5] to $21 \%$ and $32.7 \%$ respectively in 2011[4]. One quarter $(26.2 \%)$ of Sri Lankan adult population is suffering from central obesity (WC > $80 \mathrm{~cm}$ for woman and $>90 \mathrm{~cm}$ for man) and is double in females $(36.3 \%)$ compared to males $(16.5 \%)$ [5]. Overweight and obesity lead to many physical, psychological and economic consequences[6].

The risk for the non-communicable diseases (NCDs) such as cardiovascular diseases, and diabetes shows positive association with BMI[1]. NCDs are the leading cause of death in the world, responsible for $63 \%$ (36 million) of the global deaths each year[7]. The purpose of the health promotion efforts is to prevent the unhealthy weight gain and the initial step in motivating individuals to lose weight is to raise awareness of their present weight status and associated health risks[8].

Self-perception of body weight is a strong determinant of nutritional habits and weight management[9]. Lack of concern regarding own body weight put such individuals at risk for further weight gain and associated health sequences[10]. It is shown that the obese individuals with body size misperception have high prevalence of cardiovascular risk factors[11]. A study done among Sri Lankan adults showed that body weight misperception was common among underweight, healthy weight, overweight and obese categories [12]. Over 2/3 of overweight and 1/3 of obese Sri Lankan adults believe that they are appropriate weight category or underweight. Nearly two third (64\%) of overweight and obese Sri Lankans are unlikely to engage in weight control practices[12]. A misperception of own body weight is the primary factor for failures in weight management[13]. Measuring body weight on a daily basis and the ability to identify the weight changes are important for individual weight management[14]. Undergraduates are at a higher risk to acquire additional weight[15].

The transition period from high school to university seems to be linked with a decrease in physical activities and an increase in sedentary activities[16]. In a study carried out in Netherlands, it was reported that majority $(68 \%)$ of students had weight gain after university entrance[17]. During the transition from secondary school to university, students need to adapt to a new environment. Some authors have pointed out that when students fail to adapt adequately to the new environment, it could have negative consequences towards their health and weight status[15]. A study carried out among university students from 22 countries revealed that female students were more likely to perceive themselves as overweight than men and much more likely to report trying to lose weight. Furthermore, perception of overweight and attempt to lose weight were highest in the group of Asian countries where body weights are generally low, suggesting that local culture and norms could moderate attitudes to weight management[18].

This study aimed to evaluate the association between self-perception of body weight, weight management practices and measured BMI among a group of Sri Lankan university students.

\section{Methods}

\section{Study population and sampling size}

A descriptive cross-sectional study was conducted for one year from May 2016. A sample of 384 students consisting females and males were selected from the students of the BSc (Nursing) and the MBBS degree programmes. The maximum sample size was calculated for a given margin of error (d) 0.05 with the prevalence of any of the characteristics taken as $50 \%$ in the absence of similar studies in the local setting. A systematic sampling technique was used to select the subjects from the registration information kept at the university. Selected students were invited to participate in the study after written informed consent. After completion of data collection, 48 subjects were excluded from the analysis since the data given was incomplete. Therefore, data pertaining to 336 subjects only was analyzed. This study was approved by the Ethics Review Committee, Faculty of Health-Care Sciences, Eastern University, Sri Lanka (EUSL/ FHCS/ERC/2016/09). 


\section{Data collection instrument}

Data were collected using a self-administered questionnaire. Pre-testing was carried out among 15 students to validate the questionnaire for accountability and accuracy. Data included sociodemographic characters, self-perception of body weight and weight management practices.

\section{Measurements}

All anthropometric measurements were performed using standard procedure. The weight was measured with a SECA 703 wireless column scale (Hamburg, Germany). Participants were weighed wearing light cloths. The height was measured in the standing position by using SECA 703 wireless column scale (Hamburg, Germany) (without shoes) and the waist circumference was measured using a non-stretchable measuring tape at the approximate midpoint between the lower margin of the last palpable rib and the top of the iliac crest to the nearest $1 \mathrm{~cm}$, at end of the normal expiration.

\section{Body weight perception and weight management practices}

The weight perception question asked was "how do you feel about your body weight?'. Choices given were "underweight", "about the right weight", "overweight", and "very overweight". The weight management practice question asked was "what are you trying to do about your body weight?" and this question asked subjects to choose the answer from the following choices. The choices were "to lose", "to maintain", "to gain" and "doing nothing".

\section{Statistical analysis}

Subjects were classified into four groups according to their 'measured' BMI values as underweight: $<18.5$ $\mathrm{kg} / \mathrm{m}^{2}$; normal weight: $18.5-22.9 \mathrm{~kg} / \mathrm{m}^{2}$, overweight: $23.0-24.9 \mathrm{~kg} / \mathrm{m}^{2}$; and obese $>25.0 \mathrm{~kg} / \mathrm{m}^{2}[6]$. Central obesity was defined as a waist circumference $>90$ $\mathrm{cm}$ for males and $>80 \mathrm{~cm}$ for females[6]. Collected data were transferred to SPSS 16 statistical software (SPSS Inc., Chicago, IL, USA) and analyzed based on the research problem, objectives and variables. Percentages of responses were reported according to BMI and WC level and respective weight perception. For categorical variables, Pearson's chisquare test was used to describe the association. $\mathrm{P}$ values $<.05$ were considered significant.

\section{Results}

The response rate was $87.5 \%$. Among the 336 participants, majority of the participants were females $(61.0 \%)$ and fifty four percent were Sinhalese. Socio-demographic characteristics of participants are shown in Table 1.
Table 1. Socio-demographic characteristics of participants

\begin{tabular}{lcc}
\hline Variables (No=336) & Number & \% \\
\hline Gender & & \\
Male & 131 & 39.0 \\
Female & 205 & 61.0 \\
Ethnicity & & \\
$\quad$ Sinhalese & 181 & 53.9 \\
Tamils & 86 & 25.6 \\
Muslims & 67 & 19.9 \\
Burgher & 02 & 0.6 \\
Current Resident & & \\
$\quad$ Home & 54 & 16.0 \\
Hostel & 224 & 66.7 \\
Other & 58 & 17.3 \\
Meal Type & & \\
Vegetarian & 21 & 6.2 \\
Non-Vegetarian & 295 & 87.8 \\
Ovo-vegetarian & 20 & 6.0 \\
Sources of Food & & \\
Home & 64 & 19.0 \\
University Canteen & 199 & 59.2 \\
Food vendor & 53 & 15.8 \\
Made by self & 20 & 6.0 \\
\hline
\end{tabular}

The mean (SD) BMI for the study population was $22.9 \pm 3.6 \mathrm{~kg} / \mathrm{m}^{2}$. The mean BMI for males was $23.2 \pm 4.0 \mathrm{~kg} / \mathrm{m}^{2}$ and $22.8 \pm 4.9 \mathrm{~kg} / \mathrm{m}^{2}$ females. Nearly half of the study population $(n=153)$ had normal BMI while over one third $(n=118)$ were overweight. Ten percent $(n=36)$ were obese and $9 \%(n=29)$ were below normal BMI. In males, the prevalence of overweight and obesity were $33.6 \%$ and $14.5 \%$ respectively. In females, it was $36.1 \%$ and $8.3 \%$, respectively. Nearly one fifth $(n=64)$ of the study sample had central obesity: $25 \%$ of all females and $10 \%$ of all males.

Among participants, the weight misperception varied among the BMI groups (Table 2). Majority $(n=18)$ of underweight students perceived themselves correctly as being "underweight". Interestingly, 24\% $(n=37)$ of students with normal BMI perceived their body weight incorrectly: nearly $14 \%$ perceived themselves as "under-weight" and $10 \%$ believed they were overweight. In the category of overweight, nearly half of the students perceived themselves as "right weight". Moreover, two thirds $(n=28)$ of the males and a third $(n=27)$ of the females of the overweight category considered themselves as "about right weight". In the obese participants, $14 \%$ perceived themselves as "about right weight", while $25 \%(n=13)$ of the female subjects with central obesity perceived themselves as "underweight" or "normal weight". None of male students perceived the obese state differently. The subjects who perceived their weight as "overweight" or "very 
overweight" constituted over two third $(n=51)$ of the total number of students with central obesity.

Self-perception of body weight and weight management practices of the subjects showed a significant association $(\mathrm{P}<.001)$. One quarter $(n=87)$ of the participants were seen to be engaged in weight losing practices. Over two third of the participants in the perceived overweight category and majority $(n=19)$ of the participants in the perceived very overweight category tried to lose weight. Furthermore, over two thirds of both males $(n=20)$ and females $(n=32)$ who perceived themselves as overweight tried to lose weight. Only half of the perceived "very overweight" males tried to lose weight in comparison to all females in this category. Moreover, in the perceived normal weight category, $6.4 \%$ tried to lose their weight. Two times more females $(7.8 \%)$ when compared to males $(4.2 \%)$ were noted to be in this group.

Table 2. Actual BMI vs weight perception category

\begin{tabular}{|c|c|c|c|c|}
\hline \multirow[t]{2}{*}{$\begin{array}{l}\text { BMI Categories } \\
(n=336)\end{array}$} & \multicolumn{2}{|c|}{$\begin{array}{l}\text { Weight } \\
\text { Perception } \\
(\mathrm{n}=336)\end{array}$} & \multirow[b]{2}{*}{$\begin{array}{c}\text { Over } \\
\text { weight }\end{array}$} & \multirow[b]{2}{*}{$\begin{array}{c}\text { Very } \\
\text { overweight }\end{array}$} \\
\hline & $\begin{array}{l}\text { Under } \\
\text { weight }\end{array}$ & $\begin{array}{l}\text { Right } \\
\text { weight }\end{array}$ & & \\
\hline \multicolumn{5}{|l|}{$\begin{array}{l}\text { Under weight } \\
\left(<18.5 \mathrm{~kg} / \mathrm{m}^{2}\right)\end{array}$} \\
\hline Total $(\mathrm{n}=29)$ & 62.0 & 38.0 & 0 & 0 \\
\hline Male $(n=11)$ & 72.7 & 27.3 & 0 & 0 \\
\hline Female $(n=18)$ & 55.6 & 44.4 & 0 & 0 \\
\hline \multicolumn{5}{|l|}{$\begin{array}{l}\text { Normal weight } \\
\left(18.5-22.9 \mathrm{~kg} / \mathrm{m}^{2}\right)\end{array}$} \\
\hline Total $(\mathrm{n}=153)$ & 14.4 & 75.8 & 9.8 & 0 \\
\hline Male $(n=57)$ & 21.0 & 68.4 & 10.6 & 0 \\
\hline Female $(n=96)$ & 10.4 & 80.2 & 9.4 & 0 \\
\hline \multicolumn{5}{|l|}{$\begin{array}{l}\text { Over weight } \\
\left(23-24.9 \mathrm{~kg} / \mathrm{m}^{2}\right)\end{array}$} \\
\hline Total $(\mathrm{n}=118)$ & 3.4 & 46.6 & 36.4 & 13.6 \\
\hline Male $(n=44)$ & 2.3 & 63.6 & 27.3 & 6.8 \\
\hline Female $(\mathrm{n}=74)$ & 4.0 & 36.5 & 41.9 & 17.6 \\
\hline \multicolumn{5}{|l|}{$\begin{array}{l}\text { Obesity } \\
\left(\geq 25 \mathrm{~kg} / \mathrm{m}^{2}\right)\end{array}$} \\
\hline Total $(\mathrm{n}=36)$ & 2.8 & 13.9 & 66.7 & 16.6 \\
\hline Male $(n=19)$ & 00 & 5.3 & 78.9 & 15.8 \\
\hline Female $(\mathrm{n}=17)$ & 5.9 & 23.5 & 52.9 & 17.6 \\
\hline
\end{tabular}

\section{Discussion}

This study provides details regarding body weight perception and weight management practices among a single group of Sri Lankan university students. Given the evidence of increasing trend of overweight and obesity in the Sri Lankan population[4], findings from similar but larger, population based studies could be used to describe weight management practices in Sri Lankan young adults.

The present study highlights that nearly half of the study population $(n=154)$ had higher than normal BMI values; one third were overweight and $10 \%$ were obese. A study by Jayawardena et al.[4] reported a much higher percentages of obesity (29\%) among Sri Lankan in comparison to the findings from our study population $(10 \%)$. This difference may be related to the difference in the sampling method. The alarming finding in this study is that a significant proportion of students $(35 \%)$ have potential risk to become obese in future, unless appropriate action is taken. Therefore, creating awareness about their present weight status and the potential risk in future is of utmost importance to ensure safe BMI in the future.

Obesity was commoner among males (14.5\%) compared to females $(8 \%)$, similar to two other studies done in Pakistan and USA[20,21]. In contrast, some local[4] and global[1] data showed that obesity was more prevalent in females than males and females were more vulnerable to develop obesity related negative health outcomes in future. Percentage of central obesity in this study was less than that seen in other local studies[4,19]. This feature was more prevalent among females than males. It is commonly reported that generally, females are more conscious about their body weight and seek weight control strategies[22]. It has also been noted that significant percentage of female students named media and friends as the source of pressure to maintain a certain weight[23]. Fat deposition in the abdominal area carries more risk for NCDs than deposition of fat in other areas of the body[6]. Sri Lankan adults are reported to be more conscious about their waist circumference compared to their body weight[12].

One's perception of body weight could be a factor that determines whether the person adheres or not to healthy practices that keep the body weight at a medically acceptable range. Present study showed that majority $(76 \%)$ of the normal weight participants considering themselves to be "right weight". However, nearly half of the overweight subjects reporting their weight as "normal/ right weight" was concerning. Similarly, among underweight or normal weight students, nearly one fifth considering themselves to be overweight, is worrying[24]. A previous local[4] study indicated that half of the normal weight subjects perceived themselves as "underweight" and majority (85.0\%) of the overweight reported their body weight as "normal or underweight". A study conducted among university students found that females in the underweight and normal weight category perceived themselves as "overweight" and males in the obese 
category underestimated their weight as "normal weight"[18]. It is interesting to note that the majority $(85 \%)$ of the obese participants failed to identify that they are "very overweight" in both this and other local populations. Similar finding was observed in the study by Wardle et al.[18]. It is evident that obese individuals with body size misperception have a lower awareness about the consequences of obesity[11]. The present study reports that majority $(86 \%)$ of the participants in perceived overweight or very overweight category engaged in weight losing practices. In another study done among Sri Lankan adults also showed that two thirds of them in these categories tried to lose their weight[12], in contrast to a smaller proportion in perceived normal weight category, trying to lose their weight as shown in the present study. This is in contrast to just above one quarter of the underweight or normal weight students trying to loss their weight, particularly by females[24]. In comparison, our study population had better perception of their current body weight and majority of the participants who perceived themselves as overweight or very overweight engaged in weight losing practices. Majority of students in perceived normal weight had appropriate weight management practices.

Physical inactivity underpin risk of lifestyle dependent non-communicable health conditions[25]. Misperception of body weight includes overestimation of health, underestimation of risk and lower utilization of the health care systems and is one of the barriers to engage in weight management practices; therefore, public health interventions should be multifaceted to counter these effects of body size misperception[11]. Therefore, awareness programs are essential to identify healthy body weight, consequences of being overweight and obesity and healthy life style practical for this student community.

\section{Conclusions}

Almost half of the participants were overweight or obese. Abdominal obesity was seen in one fifth of the participants and it was common in females. Body weight misperception was common among overweight and obese categories. This study highlights the importance of self-awareness of body weight to maintain a healthy status.

\section{Acknowledgement}

The authors would like to acknowledge Mr.S.Santharooban for statistical support and Mrs.A.Janarthani for language editing.

\section{References}

1. World Health Organization. Overweight and Obesity. Fact sheet 2018. Available from: http:// www.who.int/mediacentre/factsheets/fs311/en (accessed 21 Dec 2018).

2. World Health Organization.10 Facts on Obesity. Available from: http://www.who.int/features/ factfiles/obesity/en// (accessed 21 Dec 2018).

3. Jayawardena R, Byrne NM, Soares MJ et al. Prevalence, Trends and associated socio-economic factors of obesity in South Asia. Obes. Facts 2013;6:405-14. doi: 10.1159/000355598

4. Jayawardena R, Byrne NM, Soares MJ et al. The Obesity Epidemic in Sri Lanka Revisited. Asia Pacific J. Public Heal 2015;27:1298-9. doi: 10.1177/1010539512464650

5. Katulanda P, Jayawardena MAR, Sheriff MHR, et al. Prevalence of overweight and obesity in Sri Lankan adults. Obes. Rev 2010;11:751-6. doi: 10.1111/j.1467-789X.2010.00746.x.

6. WHO/IASO/IOTF. The Asia-Pacific perspective: redefining obesity and its treatment. Geneva. World Health Organ 2000

7. World Health Organization. 10 facts on noncommunicable diseases. Available from: https:/www.who.int/features/factfiles/ noncommunicable_diseases/en/ (accessed 21 Dec 2018)

8. Wammes B, Breedveld B, Looman C et al. The impact of a national mass media campaign in The Netherlands on the prevention of weight gain. Public Health Nutr 2007;8:1250-7. https://doi.org/10.1079/PHN2005753

9. Brener ND, Eaton DK, Lowry R et al. The Association between Weight Perception and BMI among High School Students. Obes. Res 2004;12:1866-74. doi: 10.1038/oby.2004.232

10. Faber M, Kruger HS. Dietary intake, perceptions regarding body weight, and attitudes toward weight control of normal weight, overweight, and obese black females in a rural village in South Africa. Ethn. Dis 2005;15:238-45.

11. Powell TM, de Lemos JA, Banks K et al. Body size misperception: A novel determinat in the obesity epidermic. Arch Intern Med 2010;12:65-7. doi: 10.1001/archinternmed.2010.314.

12. Jayawardena R, Byrne NM, Soares MJ et al. Body weight perception and weight loss practices among Sri Lankan adults. Obes Res Clin Pract 2014;8:e192-200.

doi: 10.1016/j.orcp.2013.05.003. 
13. Rahman M, Berenson AB. Self-perception of weight and its association with weight-related behaviors in young, reproductive-aged women. Obstet Gynecol 2010;116:1274-80. doi: 10.1097/AOG.0b013e3181fdfc47.

14. VanWormer JJ, Linde JA, Harnack LJ et al. SelfWeighing Frequency Is Associated with Weight Gain Prevention over 2 Years Among Working Adults. Int. J. Behav. Med 2005;30:210-6. doi.org/10.1007/s12529-011-9178-1

15. Von Ah D, Ebert S, Ngamvitroj A et al. Predictors of health behaviours in college students. J. Adv. Nurs 2004;48:463-74. doi: 10.1111/j.1365-2648.2004.03229.x

16. Mazier MJP. Impact of nutrition education on university students' fat consumption. Can. J. Diet. Pract. Res 2009;70:187-92. doi: 10.3148/70.4.2009.187

17. De Vos P, Hanck C, Neisingh M et al. Weight gain in freshman college students and perceived health. Prev. Med. Rep 2015;2:229-34. doi: 10.1016/j.pmedr.2015.03.008.

18. Wardle J, Haase AM, Steptoe A. Body image and weight control in young adults: International comparisons in university students from 22 countries. Int. J. Obes 2006;30:644-51. doi: 10.1038/sj.ijo.0803050

19. Jayawardena R, Punchihewa P, Ranathunga I et al. Body weight perception among Sri Lankan cardiac patients. BMC Obesity 2016;3:32. doi: 10.1186/s40608-016-0113-5

20. Saleem MD, Ahmed G, Mulla J et al. Weight misperception amongst youth of a developing country : Pakistan -a cross-sectional study. BMC Public Health 2013;13:2-8. doi:10.1186/1471-2458-13-707

21. Wharton CM, Adams T, Hampl JS. Weight Loss Practices and Body Weight Perceptions Among US College Students. J. Am. Coll. Heal 2008;56:579-84. doi: 10.3200/JACH.56.5.579-584.

22. Marika T, Rothblum, ED. Gender differences in social consequences of perceived overweight in the United States and Australia. Sex Roles $1988 ; 18: 75-86$. doi.org/10.1111/j.1471-6402.1997.tb00132.x

23. Malinauskas BM, Raedeke TD, Aeby VG et al. Dieting practices, weight perceptions, and body composition : A comparison of normal weight, overweight , and obese college females. Nutr. J 2006;5:1-8.doi.org/10.1186/1475-2891-5-11

24. Peltzer K, Pendpid S. Trying to lose weight among non-overweight university students from 22 low , middle and emerging economy countries. Asia Pac J Clin Nutr 2015;24:177-83. doi: 10.6133/apjen.2015.24.1.16.
25. Abu-Moghli FA, Khalaf IA, Barghoti FF et al. The influence of a health education programme on healthy lifestyles and practices among university students. Int. J. Nurs. Pract 2010;16:35-42. doi.org/10.1111/j.1440-172X.2009.01801.x 